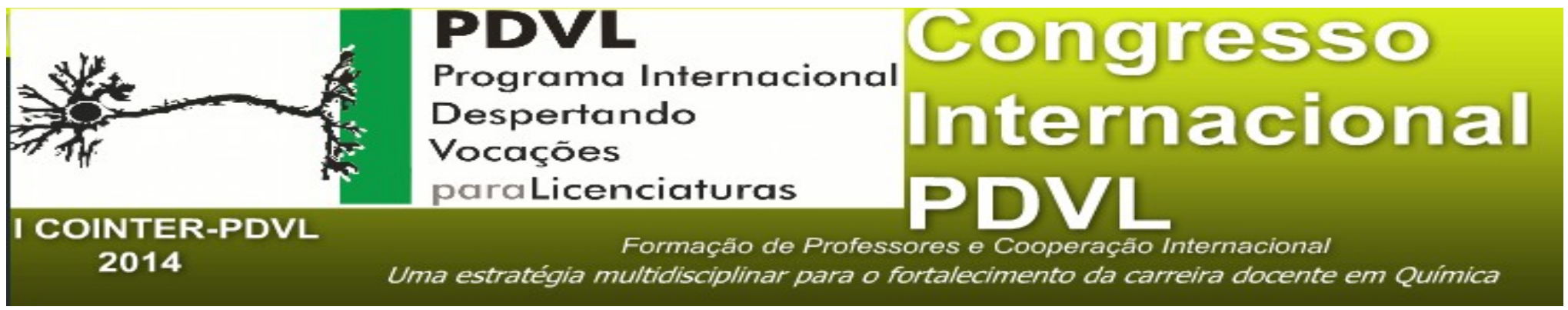

\title{
DESPERTANDO O INTERESSE CIENTIFICO DOS ALUNOS DO PRIMEIRO ANO DO ENSINO MÉDIO ATRAVÉS DE AULAS EXPERIMENTAIS.
}

\author{
Apresentação: Pôster
}

Autor $^{1}$ : Lucas de Lima Albuquerque - IFPE- Campus Vitoria. luks_la@hotmail.com;

Autor²: Leandro Soares da Silva`IFPE- Campus Vitoria. leandro00006@gmail.com;

Orientador ${ }^{3}$ : Claudio Henrique Alves Perdigão - IFPE- Campus Vitoria.

claudio.perdigao@vitoria.ifpe.edu.br

\section{Introdução}

Ainda existem alguns descasos com o ensino da Química, e um deles é o fato de professores formados em outras disciplinas estarem em sala de aula ensinando Química. Na Escola de Referencia em Ensino Médio Joaquim Olavo tem três professoras e as três são formadas em Biologia pela Universidade de Pernambuco. Esse é mais um de vários casos existentes nas escolas.

Este descaso afeta o ensino pelo fato desses professores não terem algumas fundamentações de um professor licenciado em Química, principalmente levando para o lado das aulas experimentais. Existem escolas que ainda não tem laboratórios, o que acaba dificultando a aprendizagem dos alunos. Sabe-se que a experimentação desperta um forte interesse nos alunos em diferentes níveis de escolarização, pois os 
mesmos costumam atribuir à prática experimental um caráter motivador, significativo e essencialmente vinculado aos sentidos (MARIA, et al. 2001).

As aulas experimentais são fundamentais no ensino e os alunos ficam amiúde da relação teoria pratica. Em estudos recentes, Perdigão e Lima (2010) enfatizou ganhos significativos no uso de Experimentos Demonstrativos em sala de aula, uma vez que a prática ocorre em meio à discussão teórica. Como também, em outro trabalho. Tendo em vista esses e outros problemas, esse projeto visou fomentar o entese pela química dos alunos do primeiro ano da Escola de Referencia de Ensino Médio Joaquim Olavo por meio de aulas experimentais que relacionaram a teoria com o cotidiano dos mesmos.

\section{Fundamentação Teórica}

Para a ciência progredir é necessária a obtenção de dados significativos, sendo fundamental o recurso à experimentação como forma de fazer sobressair à informação epistemológica relevante (Chalmers, 1999). Analisando epistemólogos tão diversos como Bachelard $(1981,1986)$ e a sua proposta de Materialismo Racional, Popper (1982, 1987) e a Teoria da Falsificabilidade; Kuhn (1973, 1983) e a Ciência Paradigmática, Lakatos (1989) e os seus Programas de Investigação Científica e Laudan (1984) e o seu modelo reticulado, todos reconhecem a importância da experimentação na construção do conhecimento, e são unânimes em considerar que, as atividades experimentais decorrentes em sala de aula, têm um contributo ótimo na construção do conhecimento dos alunos.

Segundo Piaget (1969, p.45), "se pretendemos formar indivíduos criativos e capazes de fazer progredir a sociedade de amanhã, é evidente que uma educação baseada na descoberta ativa da verdade é superior a uma educação que se limita a transmitir verdades e conhecimentos acabados". Esta posição reflete-se nos documentos da Reforma em que se dá ênfase a uma aprendizagem que envolva o Pensamento Criativo e a reflexão crítica a partir da experiência, enfatizando-se os processos. Na verdade, o estudo da psicologia evolutiva de Piaget (1969) evidencia bem a necessidade de concretizar o ensino, dando-lhe um cunho essencialmente experimental, embora sempre associado à argumentação teórica.

Segundo (PERDIGÃO; LIMA, (2010), “a prática experimental tem um caráter motivador, significativo e essencialmente vinculado aos sentidos.” É preciso mostrar uma visão diferente a esses alunos, uma visão de que a química é essencial não apenas para a carreira profissional, mas também no cotidiano. E de acordo com Helen Pilstrom (1991) “Só quando o próprio aluno tiver realizado uma experiência, feito as 
suas observações, e avançado conclusões sem saber a resposta de antemão, será capaz de perceber o que é a ciência”.

De acordo com (MARIA, et al. 2001). "Sabe-se que a experimentação desperta um forte interesse nos alunos em diferentes níveis de escolarização, pois os mesmos costumam atribuir à prática experimental um caráter motivador, significativo e essencialmente vinculado aos sentidos.” E em estudos recentes, Perdigão e Lima (2010) enfatizou ganhos significativos no uso de Experimentos Demonstrativos em sala de aula, uma vez que a prática ocorre em meio à discussão teórica. Como também, em outros trabalhos.

\section{Metodologia}

A pesquisa classifica-se com qualitativa, foi desenvolvido em conjunto com os discentes do primeiro ano do ensino médio da Escola de Referência em Ensino Médio Joaquim Olavo, situada na cidade Carpina-PE, que se realizou durante o período de março a maio. A partir das buscas de experimentos para fomentar o ensinoaprendizagem dos estudantes do primeiro ano, realizadas, foi selecionado um experimento para ser trabalhado. Por estarem estudando o conteúdo de misturas e densidade o experimento selecionado para ser trabalhado foi à lanterna de larva, que envolve conceitos de: misturas e densidade e interações interatômicas, elaborando-se uma leve introdução teórica, sobre os conteúdos que estão sendo trabalhado. Para esse experimento os materiais utilizados foram: Um recipiente de vidro de $6 \mathrm{~L}$, $4 \mathrm{~L}$ de óleo, $1 \mathrm{~L}$ de água de torneira e dois antiácidos analgésicos de $2 \mathrm{~g}$. E se desenvolveu em duas fases: na $1^{\mathrm{a}}$ colocou-se $1 \mathrm{~L}$ de água no recipiente de $6 \mathrm{~L}$ e após adicionou-se os $4 \mathrm{~L}$ de óleo, e explicado o que ocorre para que os líquidos não se misturem. $\mathrm{Na} 2^{\mathrm{a}}$ etapa foram observadas as densidades da água e do óleo e logo após foi colocou-se o comprimido antiácido onde se observou o efeito de larva, depois foi feita uma pequena discussão envolvendo o assunto trabalhado, em seguida foi entregue aos alunos um material contendo um breve resumo teórico, materiais utilizados e questões contextualizadas, sobre o assunto realizado.

\section{Resultados e Discussões}

Como resultado, 91\% dos alunos demonstraram muito interesse pela aula o que acaba mostrando que eles prestaram atenção, e logo após responderão corretamente as perguntas feitas nesse trabalho. Esse resultado mostra que as aulas experimentais motivam os estudantes. Quando realizadas de maneira correta, são capazes de solidificar o conhecimento teórico envolvido, os quais dificilmente seriam apreendidos sem a atividade experimental. Mais ainda, trabalhar com materiais do cotidiano facilita a identificação dos alunos com a Ciência, uma vez que passa a fazer parte de suas vidas cotidianas, tornando o conteúdo potencialmente significativo. Os estudantes mostraram-se bastantes interessados pela realização da aula experimental, fato perceptível no depoimento de um aluno: “eu tinha algumas dificuldades em aprender 
esses assuntos e realizar um experimento com esses materiais me ajudou muito" Para a professora que ensina Química no primeiro ano da escola, essa atividade experimental foi muito eficiente, de acordo com as suas palavras: "os alunos gostaram muito da aula pratica e ficaram pedindo mais”. Observamos aí uma boa evidência dos alunos para com a disciplina. De fato, a correlação teoria prática tem efeito de dinamizar o ensinoaprendizagem, tornado a disciplina mais suave. Chama-se atenção ao fato de alunos tidos como os mais distantes ou inquietos serem os primeiros a se proporem a executar o experimento. Dessa forma, a atividade experimental serviu também para promover a interação professor aluno, trabalhando a afetividade, elemento de grande importância no processo educacional.

\section{Conclusões}

Entende-se que os experimentos no ensino de Química são aqueles que instigam para a formação não apenas de um cientista, mas também de cidadãos mais conscientes. Sendo por esse e por outros motivos que essa temática deve frequentemente ser investigada, analisada e avaliada. Contribuindo para a melhoria do ensino dessa ciência tão importante e frequente em nosso dia-a-dia. Com essas atitudes esperamos poder estar contribuindo para fomentar o ensino aprendizagem dos alunos do primeiro ano do ensino médio, visto que os estudantes têm problemas ao ingressar na escola que adota um sistema integral. 


\section{Referências}

BACHELARD, G. A Epistemologia. Lisboa: Edições 70; 1981.

BACHELARD, G. O Novo Espírito Científico. Lisboa: Edições 70; 1986.

CHALMERS, A. F. What is this thing called Science? ( $3^{\mathrm{a}}$ ed.). Buckingham: Open University Press; 1999.

KUHN, T. A Tensão Essencial. Lisboa: Edições 70; 1973.

KUHN, T. La Structure des Révolutions Scientifiques. $3^{\text {a }}$ ed. França: Flammarion. 1983.

LAKATOS, I. La Metodologia de los Programas de Investigación científica. Madrid: Alianza. 1989.

LAUDAN, L. Sciences and Values. Berkeley: University of California Press. 1984.

MARIA, I. (et all). Ensino de química por meio de experimentos atrativos, simples de baixo custo. 24 Reunião Anual da Sociedade Brasileira de Química. Maio, 2001. Disponível em: www.mec.gov.br/semtec/ftp/Ciências. Acesso em: 22 de Maio de 2014.

PERDIGÃO, C. H. A; LIMA, K. S. A pratica docente experimental de Química no ensino médio. IV Colóquio Internacional Educação e Contemporaneidade. Laranjeiras Sergipe. Setembro de 2010.

PIAGET, J. Psychologie et Pédagogie. Bibliothèque Médiations. Paris: Éditions Denöel. 1969.

POPPER, K. A Lógica da Descoberta Científica. Lisboa: D. Quixote; 1987.

POPPER, K. Conjecturas e Refutações. Brasília: Universidade de Brasília; 1982. 